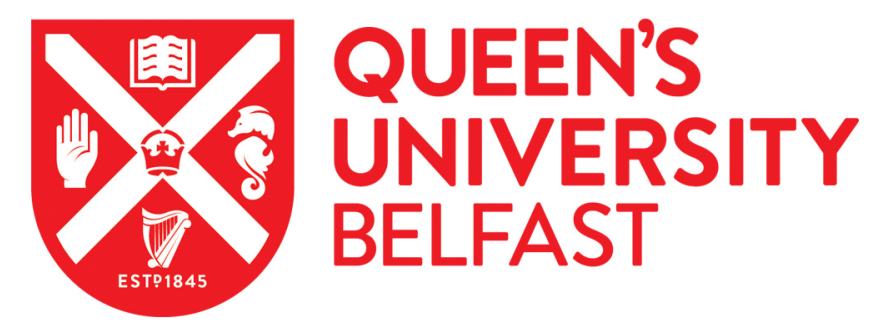

\title{
A continuous flow packed bed photocatalytic reactor for the destruction of 2-methylisoborneol and geosmin utilising pelletised $\mathrm{TiO} 2$
}

Pestana, C. J., Robertson, P. K. J., Edwards, C., Wilhelm, W., McKenzie, C., \& Lawton, L. A. (2014). A continuous flow packed bed photocatalytic reactor for the destruction of 2-methylisoborneol and geosmin utilising pelletised $\mathrm{TiO}_{2}$. Chemical Engineering Journal, 235, 293-298. https://doi.org/10.1016/j.cej.2013.09.041

Published in:

Chemical Engineering Journal

Document Version:

Peer reviewed version

Queen's University Belfast - Research Portal:

Link to publication record in Queen's University Belfast Research Portal

Publisher rights

Copyright @ 2013 Elsevier B.V.

This manuscript version is made available under the CC-BY-NC-ND 4.0 license http://creativecommons.org/licenses/by-nc-nd/4.0), which permits distribution and reproduction for non-commercial purposes, provided the author and source are cited.

\section{General rights}

Copyright for the publications made accessible via the Queen's University Belfast Research Portal is retained by the author(s) and / or other copyright owners and it is a condition of accessing these publications that users recognise and abide by the legal requirements associated with these rights.

Take down policy

The Research Portal is Queen's institutional repository that provides access to Queen's research output. Every effort has been made to ensure that content in the Research Portal does not infringe any person's rights, or applicable UK laws. If you discover content in the

Research Portal that you believe breaches copyright or violates any law, please contact openaccess@qub.ac.uk. 
1 A continuous flow packed bed photocatalytic reactor for the destruction of 2-

2 methylisoborneol and geosmin utilising pelletised $\mathrm{TiO}_{2}$.

3 Carlos J. Pestana ${ }^{a}$, Peter J. K. Robertson ${ }^{a}{ }^{*}$, Christine Edwards ${ }^{a}$, Willem Wilhelm ${ }^{b}$,

4 Craig McKenziea ${ }^{a}$ Linda A. Lawton ${ }^{a}$

5 alnnovation, Design and Sustainability (IDeaS) Research Institute, Robert Gordon

6 University, Schoolhill, Aberdeen AB10 1FR, UK

7 bWAE, Eisenhowerlaan 66, NL - 2625 GK, Delft, The Netherlands

8

$9 \quad$ *corresponding author: Tel: +44 1224 263750, Fax: +44 1224262757

10 Email: peter.robertson@rgu.ac.uk (PKJ Robertson) 
Taste and odour compounds, especially geosmin (GSM) and 2-methylisoborneol (2MIB), cause major problems in both drinking water and aquaculture industries worldwide. Aquaculture in particular has experienced significant financial losses due to the accumulation of taint compounds prior to harvest resulting in consumer rejection. UV-TiO2 photocatalysis has been demonstrated to remove GSM and 2-MIB at laboratory scale but the development of a continuous flow reactor suitable for use in water treatment has not been investigated. In this study, a pilot packed bed photocatalytic reactor was developed and evaluated for water treatment with both laboratory and naturally tainted samples. A significant reduction of both 2-MIB and GSM was achieved in both trials using the packed bed reactor unit. With the laboratory spiked water (100 ng $\mathrm{L}^{-1}$ of each compound added prior to treatment), detectable levels were reduced by up to $97 \%$ after a single pass through the unit. 


\section{Introduction}

The two most prominent members of the group of taste and odour (off-flavour) compounds are 2-methylisoborneol (2-MIB) and geosmin (GSM), both compounds can have a significant financial impact on drinking water providers as well as fish farmers $[1,2]$. They confer a musty-earthy flavour and smell to water and any produce grown in contaminated water, such as farmed fish [3, 4]. Significant financial losses are incurred by drinking water companies due to rejection of the product by customers and the need for additional treatment of water supplies [5]. Similar issues are also present in aquaculture, both in outdoor production ponds and in recirculation systems. Tainting caused from contamination with 2-MIB and GSM in aquaculture arises from the fact that even a relatively short contact time of a few hours is enough for measurable amounts to bioaccumulate in the tissue of the fish [4]. Depuration can take up to several days, provided uncontaminated water can be supplied to the fish in that period [3]. In the United States, research has mainly focused on channel catfish (Ictalurus punctatus) [6-8] where the problem has consistently increased production costs. Farmed rainbow trout and carp rearing (Onchorhynchus mykiss and Cyprinus carpio) in the UK and France have also been under investigation [911], as well as tilapia (Oreochromis niloticus) [12], 2000) and salmon (Salmo salar) [13]. The financial impact caused by the taste and odour compounds including 2-MIB and GSM cost the channel catfish rearing industry \$15 to \$ 23 million annually [2]. Therefore, it is important for the potable water and aquaculture industries to monitor and control the presence of both 2-MIB and GSM. 
There are a number of treatment strategies depending on for what the water will be used. In aquaculture, recirculation systems, employing activated carbon filters [14], and purging [15] have been explored with little success. In water treatment applications, it has been found that conventional treatment methods are ineffective in removing 2-MIB and GSM from water [16] while chemical treatment of the water by oxidation of the compounds with chlorine or ozone does not always completely remove them [17]. Treatment with activated carbon has been successfully applied [18]. The drawback of the activated carbon method is the fact that the carbon eventually saturates especially where natural organic matter (NOM) levels are high and either needs to be regenerated or destroyed by incineration or deposited in a landfill $[19,20]$. A potential alternative, or indeed supplementary treatment, could be the implementation of titanium dioxide assisted photodegradation of 2-MIB and GSM. Promising results in a lab scale study have been achieved by Lawton et al. [21] where it was shown that titanium dioxide (nanoparticulate powder) successfully decomposed both 2-MIB and GSM within 60 minutes. Further studies by this group demonstrated that the pellet form of the photocatalyst also successfully degraded geosmin $[22,23]$.

While a number of studies [21-24] have demonstrated the potential application of $\mathrm{TiO}_{2}$ photocatalysis for taint removal in batch reactors, it is desirable to develop and evaluate a continuous flow reactor since batch treatment systems would be impractical for applied applications.

In developing a photocatalytic reactor for water treatment a number of key parameters, need to be considered [25]. These include the distribution of the 
80 photocatalyst and contaminant within the water matrix, the mass transfer of the

81 target contaminant to the catalyst surface, the kinetics of the photocatalytic

82 decomposition process at the catalyst surface. A particularly critical parameter is

83 maximising the effective irradiation of the photocatalyst within the reactor unit, as the

84 kinetics of the photocatalytic process are dependent on the irradiation intensity [25].

85 Where suspended catalyst reactors have been used in the past, a significant

86 challenge has been separation of nanoparticulate $\mathrm{TiO}_{2}$ from the treated water, which

87 has greatly limited its application. Finally the capability of the unit to handle high

88 throughputs of contaminated water has proven to be a particular challenge and this

89 is strongly influenced by the parameters detailed above [25, 26].

90 This paper details the development and application of a simple modular

91 photocatalytic water treatment unit allowing easy scalability for a wide range of

92 applications, hence for the first time providing a practical solution for the removal of 93 GSM and 2-MIB in water. 


\section{Experimental}

\subsection{Materials}

The Hombikat K01/C titanium dioxide pellets were acquired from Sachtleben Chemie, Germany. These robust pellets are cylindrical in shape of between 8 and $15 \mathrm{~mm}$ in length with a diameter of $\sim 5 \mathrm{~mm}$ with a surface area of $41 \mathrm{~m}^{2} \mathrm{~g}^{-1}$ [27]. The combined 2-methylisoborneol and geosmin standards were of analytical grade and obtained from Supelco, UK. All solvents used for the analysis were analytical grade supplied by Fisher Scientific, UK and of analytical grade.

\subsection{Construction of reactor for photocatalysis}

The reactor was constructed from a sheet of double walled Plexiglas Altop ${ }^{\circledR}$ (Evonik, Germany) with >97 \% UV transmittance $(12 \times 2000 \times 900 \mathrm{~mm})$ and fifteen channels (c. $60 \mathrm{~mm}$ ) running along the lengths of the sheet. To achieve the maximum path length (i.e. $30 \mathrm{~m}$ ), $60 \mathrm{~mm}$ segments were removed from the inner vertical dividers on alternating ends of the sheet (Fig. 1). One end of the reactor was then sealed with the capping end-piece. The end-piece covering the nearest channel to the edge of the sheet was perforated to allow the outflow of the effluent. The reactor was filled with Hombikat $\mathrm{K} 01 / \mathrm{C}$ titanium dioxide pellets (c. $22 \mathrm{~kg}$ ). Once the catalyst was loaded into each channel the top was sealed with the capping end-pieces, only allowing one channel nearest the edge, diagonally opposite the outlet, to remain open to receive the tubing that would introduce the sample into the reactor (Fig. 1). The UV radiation was supplied by 12 UVB lamps (100 W per lamp, spectral output: 280 to $330 \mathrm{~nm}$ ) placed near (c. $150 \mathrm{~mm}$ ) the surface of the reactor. The reactor was mounted on marine ply cut to the same size as the reactor with a sheet of reflective 
acetate placed between the reactor and the ply to maximise reflective illumination within the reactor bed.

\subsection{Photocatalysis}

Accurately evaluating the actual removal of GSM and 2-MIB in water treatment systems is challenging, as these compounds can be lost to many surfaces [28]. To avoid sample loss due to non-specific binding (e.g. in pump tubing and plastic carboys), stainless steel pressure cans were used to hold the water prior to treatment and to apply the water to the reactor. For the laboratory evaluation 4 pressure cans were filled with $30 \mathrm{~L}$ each of Milli-RO water (Millipore) spiked with 2MIB and GSM standard to achieve a concentration of $100 \mathrm{ng} \mathrm{L}^{-1}$ of each of the offflavour compounds in the final solution. Triplicate samples $(200 \mathrm{~mL})$ were taken from each of the pressure cans to confirm the initial concentration of both analytes $\left(T_{0}\right)$. Nitrogen gas was used as propellant to drive the water through the photocatalytic reactor at a flow rate of approximately $2 \mathrm{~L} \mathrm{~min}^{-1}$. As there was limited back pressure due to the free flow of liquid through the reactor, only a small head pressure of 1-2 barr was required. Pressure was only applied immediately before treatment to prevent alteration in dissolved $\mathrm{O}_{2}$ levels. Water $(30 \mathrm{~L})$ was passed through the reactor without illumination to determine system and dark adsorption with samples (triplicate $200 \mathrm{~mL}$ ) collected directly from the outflow. To evaluate the photocatalytic removal of the 2-MIB and GSM, three $30 \mathrm{~L}$ batches were passed through the reactor at $2 \mathrm{~L} \mathrm{~min}-1$ under constant illumination. Samples $(200 \mathrm{~mL})$ were collected in triplicate as each of the three batches passed through the reactor. 
143 The photocatalytic reactor was designed for potential application in aquaculture 144 settings hence naturally tainted water from a carp rearing raceway where 2-MIB and 145 GSM were already present was used to evaluate the reactors performance. The 146 selected sampling site was a $21 \times 6 \mathrm{~m}$ indoor raceway (approximate depth $1.3 \mathrm{~m}$ )

147 which had been in operation for carp rearing for 2.5 years located in central 148 Scotland. Both GSM and 2-MIB had been previously detected at this site. The water was collected 09.03.2012 and placed directly into four $30 \mathrm{~L}$ stainless steel pressure cans. The experimental procedure was followed as per the laboratory testing with

151 spiked purified water.

154 Each sample was immediately pre-concentrated using C8 solid phase extraction 155 (SPE) cartridges (Biotage, Upsala, Sweden) where the $200 \mathrm{~mL}$ water sample was applied to the conditioned cartridge with subsequent elution in ethyl acetate (Table 1). Quantitative analysis of the samples was then carried out using a pulsed splitless injection GC-MS method (Table 2) where the analytes were detected in SIM mode [29]. 


\section{Results and discussion}

163

164

165

166

167

168

169

170

171

172

173

174

175

176

177

178

179

180

181

182

183

184

185

\subsection{Reactor Design}

The packed bed reactor configuration was designed with certain features that are important in ensuring large scale applications are viable. The photocatalytic reactor was constructed from Plexiglas which has a high transmission of UV light greater than the band gap energy required to activate the $\mathrm{TiO}_{2}$ photocatalyst (380 nm [27]). The Plexiglas also facilitates effective transmission of UVB light. Furthermore, the reactor was designed with a relatively thin catalyst bed to further enhance effective light penetration throughout the unit. The way the photocatalyst was deployed within the channels allowed flow through the catalyst bed within the unit, which has been shown to enhance mass transport properties within photocatalytic reactors $[25,26$, 30]. Although there was a relatively high loading of photocatalyst in the reactor unit (22 kg), the reactor was operated in a flow through mode pumping the water for treatment from a main reservoir. This is the type of configuration that would be adopted in a fish farm application. Using the pelletised photocatalyst material (Hombikat K01/C) the requirement for a catalyst separation step has been eliminated, which is required in packed bed units that utilise powder materials. Previous studies had demonstrated that this particular catalyst material and reactor configuration overcame the difficulties of catalyst water/separation encountered when employing nanoparticulate $\mathrm{TiO}_{2}$ and was robust, not shedding significant quantities of powdered $\mathrm{TiO}_{2}$ as has been observed for other particulate catalysts [31]. It had also previously been demonstrated that this catalyst performed well in an alternative batch reactor designed to evaluate the destruction of GSM [22]. The unpacked volume of the reactor was $21.6 \mathrm{~L}$ but when fully packed (22 $\mathrm{kg}$ of $\mathrm{TiO}_{2}$ 
pellets $=17.6 \mathrm{~L}$ ) the working fluid volume of the reactor was $4 \mathrm{~L}$ allowing a 2 minute residency at the flow rate applied $(2 \mathrm{~L} \mathrm{~min}-1)$.

\subsection{Reactor performance using laboratory water spiked with 2-MIB and GSM}

The investigation with spiked Milli-RO laboratory water demonstrates good removal of both 2-MIB and GSM (Fig. 2). Approximately $80 \%$ and $88 \%$ of the removal of 2MIB and GSM respectively can be accounted for by dark adsorption to the pelleted titanium dioxide. This is significantly higher than that observed previously for GSM and the same catalyst (10-20\% dark absorption [22]). One of the likely explanations for this significant difference could be the marked difference in catalyst load. In the work of Bellu and colleagues [22], the catalyst load related to the reaction volume was $0.75 \mathrm{~kg} \mathrm{~L}^{-1}$ compared to the current reactor with $5.5 \mathrm{~kg} \mathrm{~L}^{-1}$ providing significant increase in catalyst surface area. The flow through system also may favour dark adsorption due to the enhanced mass transport. Adsorption of the contaminant to the surface of the photocatalyst is an important first step in the photocatalytic decomposition process. It has previously been reported that for the photocatalytic destruction of microcystins, the materials that demonstrated the highest dark adsorption to the photocatalyst also displayed the most efficient photocatalytic decomposition [32]. On irradiation of the reactor unit $96 \%$ of both compounds were removed from the contaminated water sample. The photocatalyst materials were reused for treating different water samples and similar levels of dark adsorption and subsequent photocatalytic decomposition were achieved, demonstrating that the removal of both taint compounds was not purely an adsorption process; the adsorbed materials underwent subsequent photocatalytic decomposition. Bellu [33] has also observed the destruction of GSM in a bench top $\mathrm{TiO}_{2}$-UV flow-through reactor. In Bellu's [33] design the lowest flow rate $\left(0.05 \mathrm{~L} \mathrm{~min}^{-1}\right)$ achieved $67 \%$ 
removal of the original spike $\left(100 \mathrm{ng} \mathrm{L}^{-1}\right)$ for GSM with the same catalyst (Hombikat $\mathrm{K} 01 / \mathrm{C}$ ). However, when the flow rate was increased to $0.2 \mathrm{~L} \mathrm{~min}^{-1}$, a tenth of the flow rate used in the current study, the removal efficiency dropped to only $19 \%$. Some of the key differences between the two systems are the much lower catalyst load $(0.842 \mathrm{~kg})$ and the UV irradiation, which was a single UV black lamp tube (40 Watt).

One of the only other studies which evaluate $\mathrm{TiO}_{2}$ photocatalysis of both 2-MIB and GSM is an investigation by Lawton et al. [21] which reports that nanoparticulate Degussa P25 successfully degraded $>99 \%$ of 2-MIB within 30 mins, however, the complete removal of GSM took 60 mins. This is somewhat different to the identical removal rates observed here for both compounds and interestingly it is the GSM that was observed to show the highest dark absorption. Typically, the higher the dark adsorption of a compound, the more efficient the photocatalytic removal of that compound. It is also worth noting that the removal rates that were observed were highly reproducible between each batch of spiked water applied to the reactor (Fig. 2).

3.3 Reactor performance using fish farm water with naturally occurring 2-MIB and GSM

Following this successful laboratory, test investigations were carried out to evaluate the performance of the reactor using a sample typical of that which may require treatment to remove naturally occurring taint. Water was sampled from a carp rearing raceway that has been in operation for more than two years and was known to contain naturally occurring amounts of 2-MIB and GSM. As expected both compounds were detected by SPE-GC/MS in the water prior to treatment, with GSM 
levels (18.5 $\left.\mathrm{ng} \mathrm{L}^{-1}\right)$ being slightly higher than the level of 2-MIB $\left(14 \mathrm{ng} \mathrm{L}^{-1}\right)$. The water had not been pre-filtered prior to treatment so contained both dissolved and suspended matter. The reactor successfully removed the majority of the 2-MIB and GSM present in the fish farm samples (figure 3). As might be anticipated the dark adsorption, $71 \%$ for 2 -MIB and $67 \%$ for GSM, is lower than that observed for the spiked laboratory water (2-MIB: $80 \%$ and GSM: $88 \%$ ). Although the amount of the analytes in the water from the fish farm is lower (14 and 18.5 compared to $100 \mathrm{ng} \mathrm{L}-$ ${ }^{1}$ ) the reduced dark adsorption can be explained by the presence of natural organic matter (NOM) competing for the binding sites on the catalyst and hence competing in the photocatalytic decomposition process. Newcombe et al. [34, 35] have conducted a study that investigated the competition between 2-MIB and natural organic matter (NOM) for binding sites on activated carbon. It was found that NOM actively competes with 2-MIB for binding places on the activated carbon, a similar process is very likely to be happening with 2-MIB, GSM and the NOM present in the fish farm samples as they compete for sites on the $\mathrm{TiO}_{2}$. Doll and Frimmel [36] proposed that the presence of NOM and other organic substances would reduce the photocatalytic efficiency due to the obvious direct competition for active sites but also due to attenuation of the UV radiation and possibly catalyst surface deactivation.

UV Irradiation of the water as it passed through the reactor resulted in the successful elimination of $91 \%$ of the GSM (1.7 $\mathrm{ng} \mathrm{L}^{-1}$ remaining) and 84\% (2.2 $\mathrm{ng} \mathrm{L}^{-1}$ remaining) of the 2-MIB. Bellu and co-workers [33] found that their flow reactor design applied to waters from a Danish eel farm could only remove $33 \%$ of the GSM present (7 ng $\mathrm{L}^{-1}$ ) in one pass through their reactor. Bellu [33] also proposed NOM as a competitor for the photocatalytic decomposition of GSM. In that study, significant removal was 
only achieved after 3 passes through a catalyst filled glass coil resulting in a total contact time of 60 mins. The reactor in the present study showed significant improvement in treatment efficiency, achieving almost complete removal with one pass through the reactor, which took 2 mins. The performance of this reactor reduced both GSM and 2-MIB to below the level that would be likely to cause taste and odour problems in aquaculture and drinking water, where the threshold for human detection MIB/geosmin can range from 4 to $20 \mathrm{ng} / \mathrm{L}[37,38]$.

Analysis of the treated water samples, both in lab grade water and that from the fish farm, revealed no significant detectable by-products. Few studies have been published that explore the reaction by-products of 2-MIB and GSM following oxidation processes. Recently, Qi and co-workers [39] reported the production of ketoaldehydes during the ozonolysis of 2-MIB and trichloroanisole (TCA) in water. However, the yield of by-products was dependent on ozone dosage, temperature, $\mathrm{pH}$ and reaction matrix as might be expected. In the present study, the lack of detectable by-products may highlight the suitability of this systems design. The high catalyst load and flow through pattern allows the degradation of the parent compounds followed by adsorption and degradation of by-products. Other possible explanations include that the processing (SPE sample concentration) and GC-MS detection method were not optimised for by-product detection or that the activity of hydroxyl radicals result in lower yield of aldehydes [38].

\section{Conclusion}

The modular continual-flow reactor design, which is readily scalable to treat larger volumes, has successfully demonstrated the removal of both 2-MIB and GSM under 
both laboratory conditions and in the field with a contact time of only 2 mins. This

285

286

287

288

289

290

291

292

293

294

295

296

297

298

299

300

301

302

303

304 type of reactor design is a particularly effective way to deploy the catalyst in a contained unit together with the control over flow rates, mass transport limitations may be minimised. This is a particularly important consideration when new more effective photocatalysts are developed as the system should not depend on mass transport limitations and hence any benefits of enhanced photocatalytic activity with the new materials may be maximised. This design of reactor could be added within the flow stream of a typical recirculation system used in the culture of fish and evaluation of its potential application in potable water treatment should be explored. Further development and application of this technology will now be explored to evaluate the removal of other pollutants and to optimise relevant treatment parameters.

\section{Acknowledgements}

The authors would like to thank Pisces Engineering Ltd. Scotland for allowing the authors to sample water from their fish farm and Mr Leonard Montgomery for proofreading the manuscript. This is part of a larger project, which has been selected in the framework of the Dutch Operational Programme "Perspective for a sustainable Fishery" which is partly financed by the European Fishery Fund (EFF).

\section{References}


1. G. Izaguirre, C.J. Hwang, S.W. Krasner, M.J. McGuire, Geosmin and 2methylisoborneol form cyanobacteria in three water supply systems, Appl. Environ. Microbiol., 43 (1982), 708-714

2. T.R. Hanson, Economic Impact of Off-Flavor to the U.S. Catfish Industry, ACS Symposium Series 848 Off Flavours in Aquaculture, (2003) 13-29

3. P. Howgate. Tainting of farmed fish by geosmin and 2-methyl-iso-borneol: a review of sensory aspects and of uptake/depuration, Aquaculture, 234 (2004), $155-181$

4. R.F. Robertson, A. Hammond, K. Jauncey, M.C.M. Beveridge, L.A. Lawton, An investigation into the occurrence of geosmin responsible for earthy-musty taints in UK farmed rainbow trout, Onchorhynchus mykiss, Aquaculture, 259 (2006) 153-163

5. K.S. Sklenar, A.J. Horne. Horizontal distribution of Geosmin in a reservoir before and after copper treatment, Water Sci. Technol., 40 (1999), 229-237.

6. W.J. Lorio, P.W. Perschbacher, P.B. Johnsen. Relationship between waterquality, phytoplankton community and off-flavours in channel catfish (Ictalurus punctatus) production ponds, Aquaculture, 106 (1992), 285-292

7. E.D. Conte, S.C. Conway, D.W. Miller, P.W. Perschbacher. Determination of methylisoborneol in channel catfish pond water by solid phase extraction followed by gas chromatography-mass spectroscopy, Water Res., 30 (1996) 2125-2127

8. K.K. Schrader, B.W. Green, P.W. Perschbacher. Development of phytoplankton communities and common off-flavours in a biofloc technology system used for the culture of channel catfish (Ictalurus punctatus), Aquacult. Eng., 45 (2011) 118-126 
9. R.F. Robertson, L.A. Lawton. Off flavour problems and a potential solution within the U.K. trout industry, ACS Symposium Series 848 Off Flavours in Aquaculture, (2003) 55-68.

10. J. Robin, J. Cravedi, A. Hillenweck, C. Deshayes, D. Vallod. Off flavor characterization and origin in French trout farming, Aquaculture, 260 (2006), 128-138

11. D. Vallod, J.P. Cravedi, A. Hillenweck, J. Robin. Analysis of the off-flavour risk in carp production in ponds in Bombes and Forez (France), Aquacult. Int., 15 (2007) 287-298.

12. J. Yamprayoon, A. Noomhorm. Geosmin and Off-Flavor in Nile Tilapia (Oreochromis niloticus), Aquatic Food Prod. Technol., 9 (2000), 29-41

13. L. Farmer, J.M. McConnell, T.D. Hagan, D.B. Harper, Flavour and off-flavour in wild and farmed Atlantic salmon from locations around Northern Ireland, Water Sci. Technol., 31 (1995) 259-264

14. C.S. Tucker, Off-flavours in aquaculture, Rev. Fisheries Sci., 8 (2010) 45-88

15. L. Guttman, J. Van Rijn. Identification of conditions underlying production of geosmin and 2-methylisoborneol in a recirculating system, Aquaculture, 279 (2008) 85-91

16. R. Nerenberg, B.E. Rittmann, W.J. Soucie. Ozone/biofiltration for removing MIB and geosmin, J. American Water Works Ass. J, 92 (2000), 85-95

17. W.H. Glaze, R. Schep, W. Chauncey, E.C. Ruth, J.J. Zarnoch, E.M. Aieta, C.H. Tate, M.J. McGuire, Evaluating oxidants for the removal of taste and odor compounds from a municipal water-supply, J. American Water Works Ass., 82 (1990), 79-84 
18. D. Cook, G. Newcombe, P. Sztajnbok. The application of powdered activated carbon for MIB and geosmin removal: Predicting PAC doses in four raw waters, Water Res., 35 (2001) 1325-1333

19. G. San Miguel, S.D. Lambert, N.J.D. Graham. The regeneration of field-spent granular-activated carbons, Water Res., 35 (2001), 2740-2748

20. J.T.E. Chestnutt, M.T. Bach, D.W. Mazyck. . Improvement of thermal reactivation of activated carbon for the removal of 2-methylisoborneol, Water Res., 41 (2007) 79-86

21. L.A. Lawton, P.K.J. Robertson, R.F. Robertson, F.G. Bruce. The destruction of 2-methylisoborneol and geosmin using titanium dioxide photocatalysis, Appl. Catal. B: Environmental, 44 (2003) 9-13

22. E. Bellu, L.A. Lawton, P.K.J. Robertson, Photocatalytic destruction of geosmin using novel pelleted titanium dioxide, J. Adv. Oxid. Technol., 11 (2008), 384-388

23. P.K.J. Robertson, D.W. Bahnemann, L.A. Lawton, E. Bellu. . A study of the kinetic solvent isotope effect on the destruction of microcystin-LR and geosmin using $\mathrm{TiO}_{2}$ photocatalysis, Appl. Catal. B: Environmental, 108 (2011) $1-5$

24. S. Yoon, Y.H. Lee, W. Cho, I. Koh, M. Yoon. Synthesis of $\mathrm{TiO}_{2}$-entrapped EFAL-removed Y-zeolites: Novel photocatalyst for decomposition of 2methylisoborneol, Catal. Commun., 8 (2007) 1851-185

25. C. McCullagh, N. Skillen, M. Adam, P.K.J. Robertson, Photocatalytic reactors for Environmental Remediation: A review, Journal of Chemical Technology and Biotechnology, 86 (2011) 1002-1017. 
26. C. McCullagh, P.K.J. Robertson, M. Adams, I. Campbell, P. Pollard, A. Mohammed, Development of a slurry continuous flow reactor for photocatalytic treatment of industrial waste water, J. Photochem. Photobiol., A. Chem. 211 (2010) 42-46.

27. F. Wood, The photocatalytic destruction of volatile organic compounds generated by the oil and gas industry, PhD Thesis, Robert Gordon University, Aberdeen (2011)

28. S.L.N. Elhadi, P.H. Huck, R.M. Slawson, Determination of system losses of geosmin and MIB in bench-scale filtration apparatus, Water Qual. Res. J. Canada 39 (2004) 207-212.

29. C. J. Pestana, Monitoring and regulating cyanobacterial metabolites (microcystins and geosmin) in aquatic systems. PhD Thesis, Robert Gordon University, Aberdeen (2012)

30. O. A. Salu, M. Adams, P.K.J. Robertson, L.S. Wong, C. McCullagh. Remediation of oily wastewater from an interceptor tank using a novel photocatalytic drum reactor, Desalination and Water Treatment Science and Technology, 26 (2011) 1-5.

31.I. Liu, L.A. Lawton, D.W. Bahnemann, L. Liu, B. Proft, P.K.J Robertson, The photocatalytic decomposition of microcystin-LR using selected titanium dioxide materials, Chemosphere, 76 (2009) 549-553.

32. L. A. Lawton, P.K.J. Robertson, B.J.P.A. Cornish, I.L. Marr, M. Jaspars, Processes influencing surface interaction and photocatalytic destruction of microcystins on titanium dioxide photocatalysts, Journal of Catalysis, 213 (2003) 109-113. 
33. E. Bellu, Detection, analysis, and photocatalytic destruction of the freshwater taint compound geosmin. PhD Thesis, Robert Gordon University, Aberdeen, Scotland (2007)

34. G. Newcombe, J. Morrison, C. Hepplewhite. Simultaneous adsorption of MIB and NOM onto activated carbon. I. Characterisation of the system and NOM adsorption, Carbon, 40 (2002) 2135-2146

35. G. Newcombe, J. Morrison, C. Hepplewhite, D.R.U. Knappe. Simultaneous adsorption of MIB and NOM onto activated carbon II. Competitive effects Carbon, 40 (2002) 2147-2156.

36. E.T. Doll, F.H. Frimmel, Photocatalytic degradation of carbamazepine, clofibricacid and iomeprol with P25 and Hombikat UV100 in the presence of natural organic matter (NOM) and other organic water constituents, Water Res. 39 (2005) 403-411

37. M. Pirbazari, V. Ravindran, B.N. Badriyha, S. Craig, M.J. McGuire, GAC adsorber design protocol for the removal of off-flavors, Water Research, 27 (1993) 1153-1166.

38. S.W. Lloyd, J.M. Lea, JP.V. Zimba, C.C. Grimm, Rapid analysis of geosmin and 2-methylisoborneol using solid phase mirco extraction procedures, Water Research, 32 (1998) 2140-2146.

39. F. Qi, B.B. Xu, L. Feng, Z.L. Chen, L.Q. Zhang, D. Z . Sun, Formation of aldehyde during ozonation of taste and odour compounds in water. Journal of Water Supply Research and Technology-Aqua, 62 (2013) 120-128. 
427

428

429

430

431

432

433

434

435

436

437

438

439

440

441

442

443

444

445

446 
447 Fig. 1 a). Photocatalytic reactor used for the photocatalysis of 2-MIB and GSM over 448 titanium dioxide in pellet form, for both spiked laboratory and environmental (fish 449 farm) samples. b) Side cross section view of reactor.

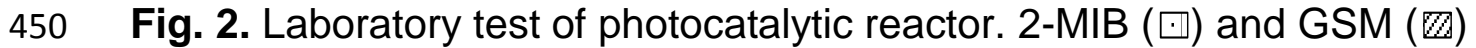
451 concentrations at $T_{0}$ and after one pass through the photocatalytic reactor. Sample 452 1: no irradiation, samples 2-4: irradiation. Initial concentration of 2-MIB and GSM:

$453100 \mathrm{ng} \mathrm{L}^{-1}$. Error bars=1 SD; $n=3$.

454 Fig. 3. Results of the fish farm test of the photocatalytic reactor. 2-MIB ( $\square)$ and GSM 455 (ख) concentrations at $\mathrm{T}_{0}$ and after one pass through the photocatalytic reactor. 456 Sample 1: no irradiation, samples 2-4: irradiation. Error bars=1 SD; $n=3$. 


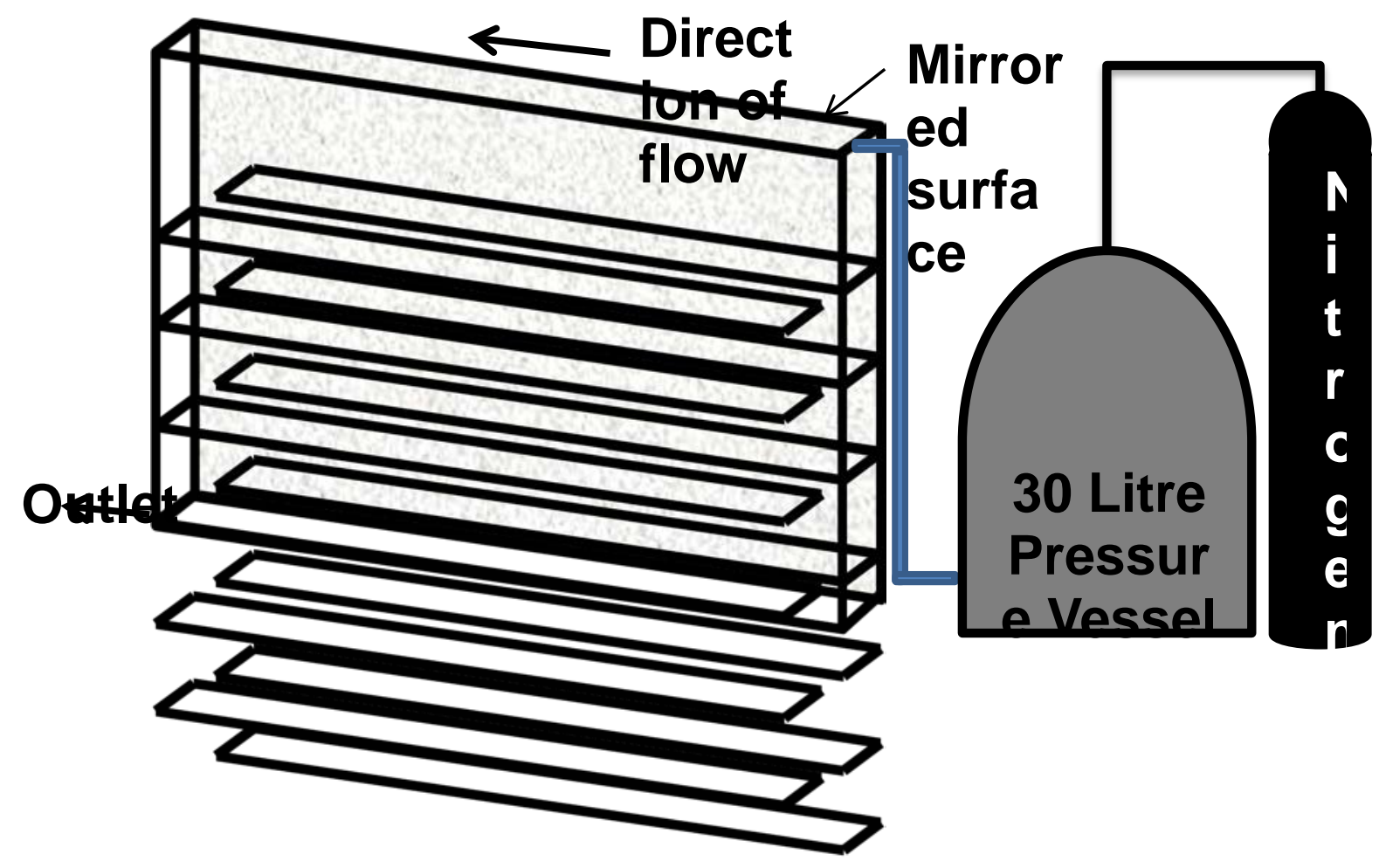

460 Fig 1 a) 


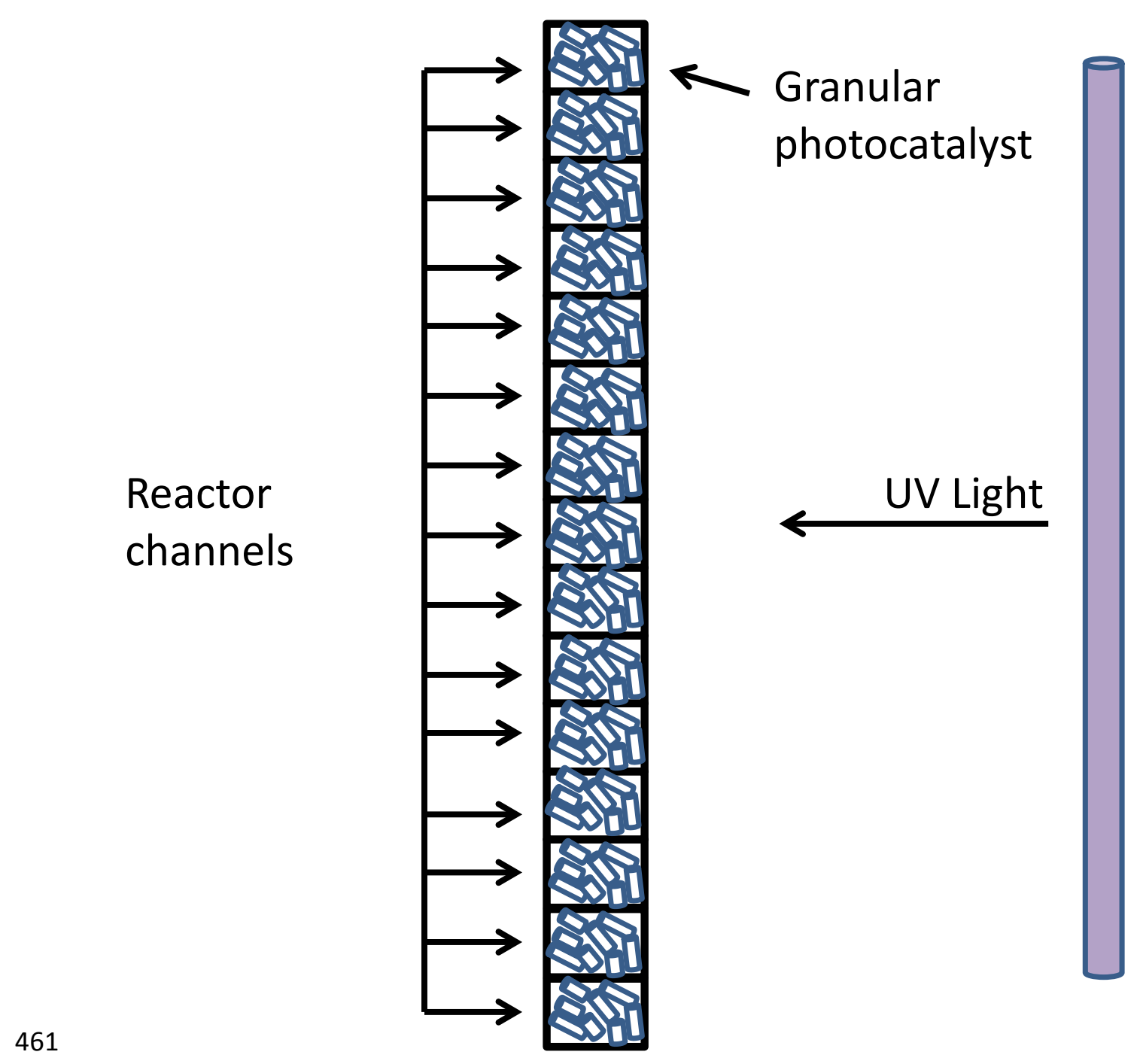

$462 \quad$ Fig 1 b) 


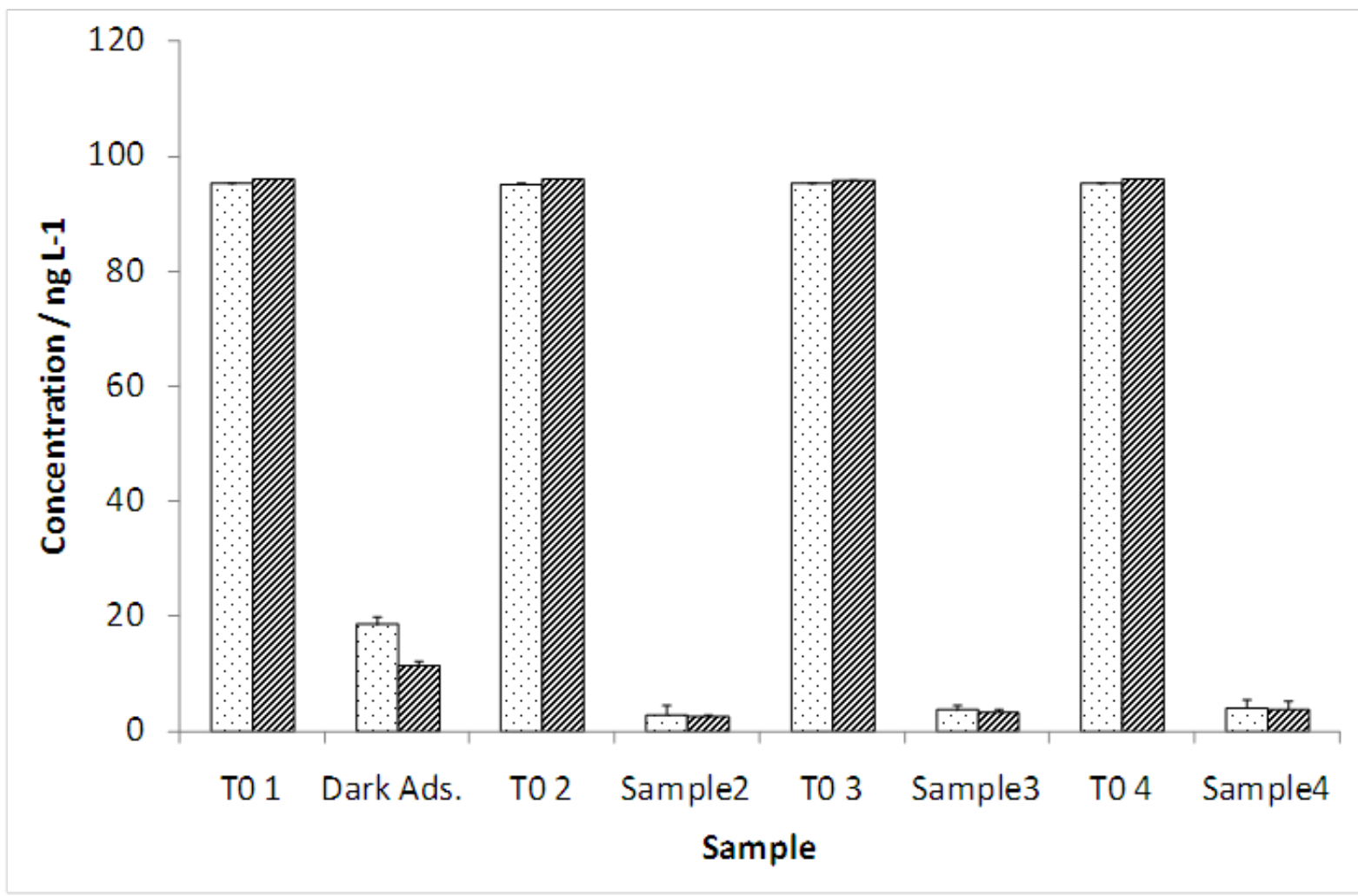

464

Fig 2.

466 


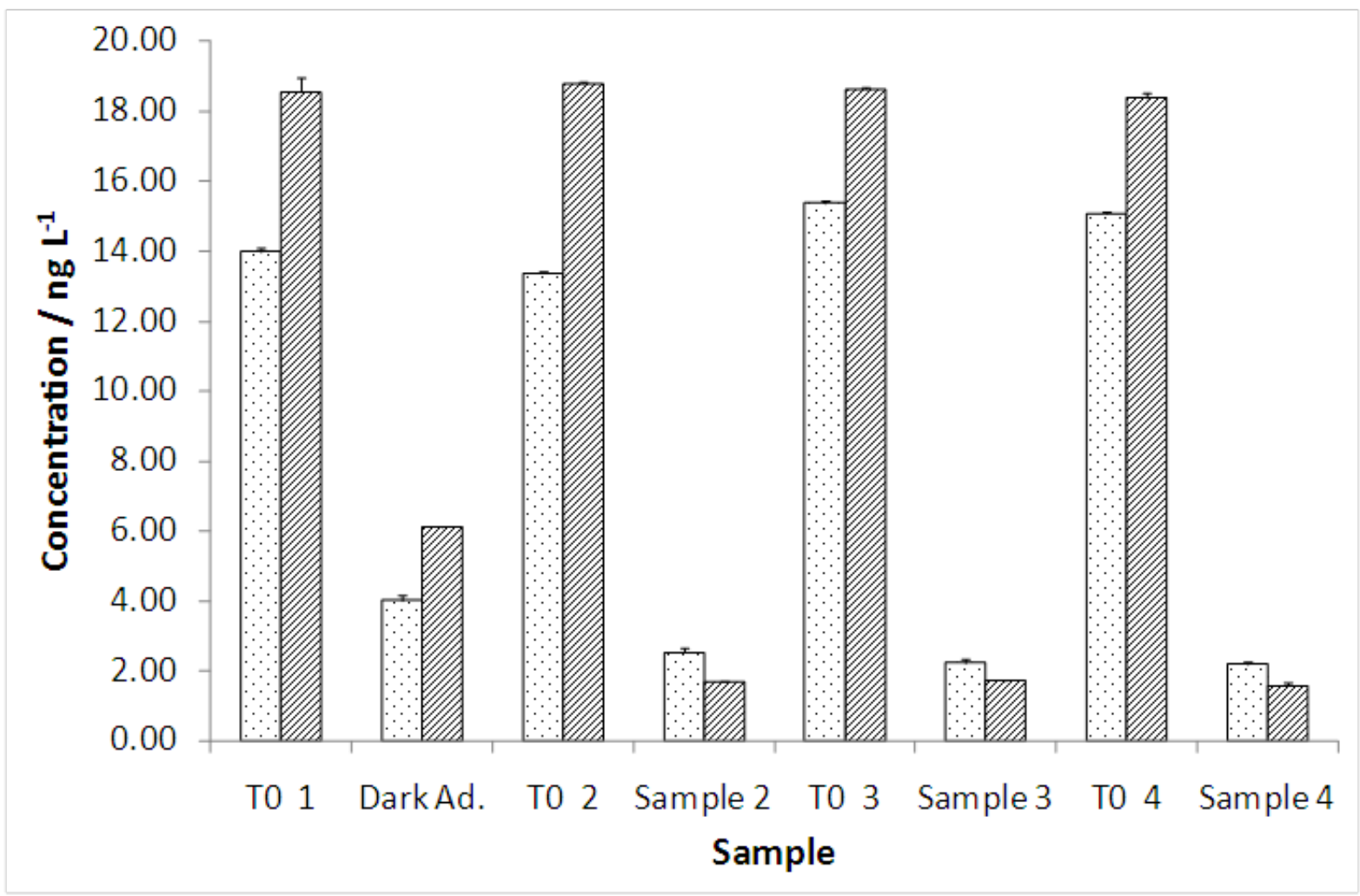

$468 \quad$ Fig 3.

469

470 
471 Table 1 SPE method for the pre-concentration of 2-MIB and GSM

\begin{tabular}{l|l}
\hline SPE parameter & Applied in this method \\
\hline Sorbent material & C8 (Biotage) \\
Sorbent load & $100 \mathrm{mg}$ \\
Cartridge volume & $1 \mathrm{~mL}$ \\
End-capped & Yes \\
Conditioning & $2 \mathrm{~mL}:$ Hexane, Acetone, Methanol; $10 \mathrm{~mL}$ : Milli-Q \\
Mode of loading & PTFE tubing with vacuum suction \\
Sample volume & $200 \mathrm{~mL}$ \\
Drying time & $5 \mathrm{~min}$ \\
Elution solvent & Ethyl acetate \\
Elution solvent volume & $0.5 \mathrm{ml}$ (+0.05 mL TCA internal standard) \\
Concentration achieved & $363: 1$ \\
\hline
\end{tabular}

472

473 
474 Table 2 Parameters for GC-MS (Agilent 6890A).

\begin{tabular}{|c|c|}
\hline Parameter & Optimised method \\
\hline \multicolumn{2}{|l|}{ Front inlet parameters } \\
\hline Injection mode & Pulsed splitless \\
\hline Injection temperature & $250{ }^{\circ} \mathrm{C}$ \\
\hline Inlet pressure & 10 psi \\
\hline Injection (pulsed) pressure & 25 psi \\
\hline Pulse time & $0.5 \mathrm{~min}$ \\
\hline Injection volume & $3 \mu \mathrm{L}$ \\
\hline Gas type & Helium \\
\hline \multicolumn{2}{|l|}{ Column } \\
\hline Column type & Capillary column \\
\hline Column length & $30 \mathrm{~m}$ \\
\hline Column diameter & $250 \mu \mathrm{m}$ \\
\hline Film thickness & $25 \mu \mathrm{m}$ \\
\hline Pressure & 10 psi \\
\hline \multicolumn{2}{|c|}{ Mass spectrometer - quantification ions (SIM) } \\
\hline 2-methylisoborneol & $95,107,135$ \\
\hline Trichloroanisole (Internal Standard) & $167,195,210$ \\
\hline Geosmin & $112,125,182$ \\
\hline \multicolumn{2}{|l|}{ Temperature program } \\
\hline Initial temperature & $60^{\circ} \mathrm{C}$ \\
\hline 0 - $1 \mathrm{~min}$ & $60^{\circ} \mathrm{C}$ \\
\hline $2-3 \mathrm{~min}$ & $20^{\circ} \mathrm{C} \mathrm{min}^{-1}$ (to reach $100^{\circ} \mathrm{C}$ ) \\
\hline $4-10 \mathrm{~min}$ & $7.5^{\circ} \mathrm{C} \min ^{-1}$ (to reach $152^{\circ} \mathrm{C}$ ) \\
\hline $10-12 \mathrm{~min}$ & Hold temperature $\left(152^{\circ} \mathrm{C}\right)$ \\
\hline
\end{tabular}

